\title{
К ВОПРОСУ ПРИМЕНЕНИЯ ПАЦИЕНТООРИЕНТИРОВАННОГО МЕНЕДЖМЕНТА ОРГАНИЗАЦИЯМИ ЗДРАВООХРАНЕНИЯ
}

\author{
(C) 2021 Гуськова Марина Федоровна \\ доктор экономических наук, профессор, профессор кафедры «Менеджмент качества» \\ Российский университет транспорта, Россия, Москва \\ (C) 2021 Зубков Александр Данилович \\ доцент кафедры анализа и прогнозирования \\ Московский Государственный Медико-Стоматологический Университет имени А.И. Евдокимова, \\ Россия, Москва
}

\section{(c) 2021 Стерликов Павел Федорович}

доктор экономических наук, профессор, заведующий кафедрой «Экономическая теория» Московский Государственный Медико-Стоматологический Университет имени А. И. Евдокимова, Россия, Москва

\section{(c) 2021 Стерликов Федор Павлович}

пачальник отдела планирования и стандартизации управления организации обеспечения деятельности медицинских организаций НИИ ОЗММ Департамента здравоохранения города Москвы, Россия, Москва

E-mail: niiozmm@zdrav.mos.ru

\section{(c) 2021 Стерликов Федор Федорович}

доктор экономических наук, профессор, лауреат премии Правительства РФ в области науки и техники, профессор ОЧУ ВО ГСИ

Гуманитарно-социальный институт, Россия, Красково

E-mail: OET2004@yandex.ru

Исследуются возможности использования базовых принципов клиентоориентированного менеджмента для организации пациентоориентированного менеджмента в здравоохранении при лечении соматических заболеваний.

Ключевые слова: клиентоориентированный менеджмент, пациентоориентированный менеджмент, соматичексие заболевания, активизация участия пациентов в процессе лечения.

\section{Вступление}

Под менеджментом в данной статье мы принимаем такую организацию производства, которая обеспечивает максимально эффективное использование имеющихся ресурсов для удовлетворения потребностей членов общества. При этом понимая под производством - «процесс создания человеческим трудом благ для удовлетворения человеческих потребностей» (Большая российская энциклопедия, Г.Д.Гловели). Производство при этом подразделяется на два вида: производство материальных благ и производство нематериальных благ. К нематериальному производству чаще всего относят и здравоохранение.

Продукт труда работников отрасли деятельности - здравоохранения принимает форму медицинской помощи. Результат труда здесь не заканчивается непосредственно лечением (услугой врача), но продолжается выполнением пациентом рекомендаций врача (снамнеза).

\section{1. Клиентоориентированный менед-} жмент

На порталах непрерывного медицинского образования много говорят о пациентоориентированности. Пациентоориентированность это основополагающий тренд современной медицины. Врачей и медсестер в тоже время приглашают на тренинги по клиентоориентированию.

Для формирования компетенции пациентоориентированности организуют тренинги по клиентоориентитрованию. Возникает вопросы: 
«Это одно и тоже понятие или это различные понятия?», «Каковы различия этих понятий?». Попытаемся разобраться в этом подробнее.

Ориентированность на интересы получателей медицинской помощи медицинскими организациями в современной учебной литературе достаточно подробно описана, а у студентов медвузов формируются соответствующие компетенции.

Первоначально была разработана система управления взаимоотношениями с клиентами для производственных предприятий, включающая программное обеспечение процесса автоматизации стратегий взаимодействия с заказчиками (клиентами) ориентированная на повышение уровня продаж, оптимизацию применяемого маркетинга, улучшение обслуживания клиентов. Для этого предприятие накапливает и сохраняет информацию о своих клиентах и историю взаимоотношений с ними, непрерывно совершенствует бизнес-процесс с последующим анализом результатов. Основное правило клиентоориентированных предприятий - «Клиент всегда прав, если это ваш клиент». И если клиент попадает в эту целевую аудиторию, то нужно исполнять все его желания и сохранить его в составе этой аудитории на долгое время. В дальнейшем именно эта аудитория клиентов принесет большую часть прибыли предприятию.

Статистика показывает, что 80\% прибыли компании обеспечивает 20\% клиентов (Gartner). Именно отношениям с этой группой клиентов и нужно уделить основное внимание. Угождать этим клиентам выгодно, так как привлечение новых клиентов обходится в пять раз дороже, чем удержание старых (по данным консалтинговой компании Gartner). Сохранить 5\% клиентов значит обеспечить увеличение прибыли до 95\% (по данным консалтинговой компании (Invesp). [Подробнее на РБК: https://trends.rbc.ru/trends/educat ion/60658f979a7947641228d4bd].

Таким образом, мы понимаем клиентоориентированность как фундаментальный подход с измеримой пользой, стремление угождать желаниям клиентов, с тем, чтобы удовлетворить их с максимальной пользой. Это альтернатива продуктовым подходам «Продать можно все», когда компании сначала создают продукт, а уже потом решает «Кому его продать». В клиентоориентированном подходе начальный пункт действий - удовлетворение желаний клиента. А финишная точка размышления - исполнять желания только тех клиентов, кто входит в целевую аудиторию и приносит прирост прибыли в долгосрочной перспективе. Прибыль при этом растет, за счет того, что клиентоориентированность удерживает или увеличивает количество постоянных клиентов и уменьшает отток покупателей. Таким образом отслойка конкурентов обеспечивается в качественной, а не в количественной плоскости. Здесь бизнес сосредотачивается на специфических потребностях целевой рыночной аудитории.

Отмеченную логику действий бизнеса предложил экономист Питер Друкер. «Клиент определяет бизнес», - написал он в книге «Практика менеджмента» еще в 1954 году. Неважно, что компания считает ценностью своего товара, главное это то, за что платит клиент. И предназначение бизнеса - соответствовать запросам клиента. Если нет дополнительной прибыли от вложения ресурсов в качественный сервис, то нет и клиентоориентированности процессов с ориентацией на запросы конечного потребителя.

Итак, высокая оценка клиентооринтированности определяется - приростом прибыли в долгосрочной перспективе, а это в медицине происходит в том случае, когда клиент снова обращается к производителю услуг. А в этом заинтересованы, чаще всего, организации рыночной части медицины.

\section{2. Пациентоориентированный менед-} жмент

Пациентоориентированность - это основополагающий тренд современной медицины Врачи и медсестры проходят обучение на тренинге по клиентоориентированию, организованном Департаментом здравоохранения города Москвы. Сегодня пациент хочет больше знать о своем здоровье - это его право, что, в свою очередь, требует от специалистов владения навыками коммуникации. Но, к сожалению, нередко врач недостаточно правильно и доходчиво доносит сложную медицинскую информацию до пациента.

Поверхностно умозрительно пациентоориентированность иногда описывают упрощенно, не касаясь самого лечения, а только говоря о материальных условиях поликлиники или больницы. «На входе установлены широкие распашные двери, оборудован современный пандус, который соответствует всем современным требова- 
ниям, по ширине и углу наклона установлены разноуровневые поручни, что актуально для маломобильных граждан. На первом этаже размещена зона ресепшена. В поликлинике появился буфет, где пациенты, которым запланировано проведение анализов и диагностики, смогут перекусить. Также здесь оборудованы кабинет дежурного врача, аптечный пункт. На втором этаже ведут прием врачи общей практики и терапевты, имеются три комфортные зоны ожидания. На третьем этаже размещены кабинеты узких специалистов. Благодаря новому оборудованию врачи поликлиники могут проводить современную диагностику, в том числе суточный мониторинг артериального давления, эхокардиографию, ультразвуковые исследования и многие другие. Четвертый этаж - зона дневного стационара, кабинеты администрации, врачейметодистов, а также картохранилище. Кроме того, в здании установлено два лифта: обычный и для маломобильных пациентов» [Из публикаций журналов].

На самом деле, содержание пациентооринтированности составляет организация получения позитивного результата для пациента, имея в виду, что материальные затраты обесечены должным образом. а не для организаций рыночного сектора здравоохранения.

Итак, высокая оценка пациентооринтированности - повышение результативности медицинского обслуживания, которое проявляется в том, что пациент реже обращается за медицинской помощью. В пациентооринтированности заинтересованы, больше всего, организации государственного сектора медицины.

\section{3. Ценностноориентированная деятель- ность}

Не умаляя значения клиентооринтированности и пациентооринтированности в практике современной медицинs, хотелось бы привести в систему понимание и практические действия организаций здравоохранения.

Давно известно, что все продукты труда (товары или услуги) обладают двумя свойствами - приносимой пользой при использовании и затратами труда на изготовление, или в современном переводе на русский язык - полезностью и стоимостью. [Адам Смит. Исследование о природе и причинах богатства народов». Глава V «О действительной и номинальной цене товаров, или о цене их в труде и цене их в деньгах»].
Доказано, что ценность продукта труда, обозначающая признание его значимости, зависит прямо пропорционально от полезности и обратно пропорционально от стоимости.

\section{Ценность $=$ Полезность $/$ Стоимость}

Признание значимости продукта труда с точки зрения покупателя (потребителя) выражается в проявлении спроса на результат труда, который зависит от качества и цены товара.

$$
\text { Спрос = Качество / Цена }
$$

Возвращаемся к ценности результатов труда организаций здравоохранения и спросу на них. Подробнее проанализируем значения клиентооринтированный и пациентоориентированный подходы в деятельности медицинских организаций. На самом деле с научной точки значения клиентооринтированный подход точнее следует называть ценоориентированным. Ценностноориентированный же подход отражает оба названных подхода - и клиентооринтированный и пациентоориентированный.

Ценностноориентированный подход = Пациентоориентированный подход / Клиентооринтированный подход

И, строго говоря, ценностноориентированный подход должен уделять необходимое внимание и обеспечению полезности медицинской услуги для пациента и обоснованному сокращению затрат на медицинскую услугу.

Поэтому формирование необходимых концепций врачам и медсестрам, работающим в государственных или частных медицинских организациях, при проведении курсов повышения квалификации необходимо четко различать применимость тех или иных приемов так называемых клиенто- или пациенто-ориентированных подходов. Во всяком случае, обращать внимание слушателей курсов на результативность применения тех или иных приемов для обеспечения эффективности деятельности государственных или частных медицинских организаций.

4. Особенности пациентоориентированного подхода при лечении соматических заболеваний.

Работники здравоохранения, стараясь по- 
мочь травмированному человеку, опираются чаще всего на известные им знания и теории, отвлекаясь от деталей человеческого самочувствия. Эффективно помочь травмированному человеку можно только если учесть в терапии, например, травмы также накопленный опыт больного как образы, чувства и ощущения, опыт переживания травм.

Посттравматические состояния отличаются ригидностью в отношениях с самим собой. Люди в этих состояниях перестают спонтанно реагировать на обстоятельства и действуют согласно шаблонам, которые мешают творческому подходу к осознанности ситуации. Осознанность же запускает процесс самоисцеления, который блокирован после травмы.

Благодаря такому осознаванию наше сознание может двигаться от хаоса и ригидности к согласованному функционированию вместе с телом. Такое осознавание своего тела, или соматическое переживание, способно погружать человека в состояния самоисцеления.

Эти аспекты и учитывает соматическая терапия, поэтому фокусом работы своей делает так называемое соматическое сознание, интеграцию всех элементов опыта человека. Это является очень хорошим практическим, действенным инструментом в исцелении травмы.

Поэтому очень важна активизация участия пациента в лечении соматических заболеваний. И особенно очень важна эмпатия врача - это осознанное сопереживание эмоциональному состоянию других людей, способность распознать, что они чувствуют, и выразить сострадание.

В последнее время мы забыли этот важнейший фактор благополучия и здоровья человека - связь телесных ощущений, соматического состояния и психологического здоровья. К счастью, современная наука снова обратилась к центральной роли тела в создании эмоций и смыслов, значит, и потребностей, ведь именно тело является источником всего этого. Именно тело резонирует с нашим эмоциональным состоянием и отражает его, поэтому совершенно несправедливо было бы забывать о том, что наша психика телесна.

Эти аспекты и учитывает соматическая терапия, поэтому фокусом работы своей делает так называемое соматическое сознание, интеграцию всех элементов опыта человека. Это является очень хорошим практическим, действенным инструментом в исцелении травмы.
Не вдаваясь дальше в тонкости психологии больного рассмотрим некоторые примеры отношений доктора и больного.

Личный опыт нахождения в хирургических отделениях показал связь результата хирургического вмешательства с предоперационным настроением больного. Высокое доверие больного хирургу (лечащему врачу), как правило, заканчивается успешным выздоровлением, неоправданные же сомнения и ожидания - различными осложнениями. Поэтому мы считаем оправданным определенное внимание на курсах повышения квалификации по взаимодействию врача с больным.

Но это взаимодействие не ограничивается личным контактом. Ведь пройдя курс лечения больной получает на руки анамнез, где отмечено «совокупность сведений о больном и развитии заболевания, ...используемых для установления диагноза и прогноза болезни, а также выбора оптимальных методов ее лечения и профилактики» (Большая Медицинская энциклопедия). Через анамнез продолжается позитивное взаимодействие врача с больным.

И здесь хотелось бы высказать некоторые замечания по содержанию анамнеза и пожелания по составу рекомендаций.

Лаконичная запись врача не всегда хорошо понятна пациенту - бывшему больному. Непонятна связь, рекомендуемых к приему лекарств, с конкретными видами недугов и их ранжирование. А это зачастую приходится пациенту знать и учитывать при получении в дальнейшем профилактических услуг.

Было время, когда врач составлял два вида анамнеза: для врача и для медицинских сестер. Сейчас медицинские сестры получают высшее медицинское образования и необходимость во втором анамнезе отпала.

Мы считаем необходимым в дальнейшем составление двух вариантов анамнеза: один для врача и другой для пациента.

Реализация глобальных планов информатизации (цифровизации) позволит в будущем реализовать это предложение без затрат дополнительного времени на составление второго анамнеза. Врач для этого должен иметь в своем распоряжении достаточно информации и о видах болезни и степени их выраженности.

Располагая такой информацией, понятной неискушенному пациенту, врач может нажатием соответствующих кнопок на компьютере 
Таблица 1. Примерная схема информации о болезни

\begin{tabular}{|c|c|c|c|c|c|}
\hline Виды болезни & а & б & в & .. & у \\
\hline 1 & & & & & \\
\hline 2 & & & & & \\
\hline 3 & & & & & \\
\hline 4 & & & & & \\
\hline $\mathrm{x}$ & & & & & \\
\hline
\end{tabular}

сформировать необходимый анамнез.

Над необходимым содержании информации и её достоверностью еще требуется поработать. Но полезность такой информации не вызывает сомнения. Врач может меньше времени тратить на составление анамнеза. Пациент получит соответствующую информацию, которую он будет использовать повседневно. Индивидуальная особенность пациента, если она ярко выражена, можно учесть в дополнительных замечаниях и индивидуальный подход к пациенту обеспечить непременно.

\section{К выводам}

Обеспечение комплайенса - согласия пациента на лечение, сотрудничество с врачом и выполнение всех требований терапии, т.е. длительное взаимодействие пациента и врача.

Обеспечение гомеостаза - способности организма пациента воспринимать происходящие в нем изменения и активировать механизмы, препятствующие этим изменениям, и, тем самым, поддерживать относительное постоянство внутренней среды, т.е. длительное существование пациента без помощи врача.

Восстановление механизмов саморегуляции, направленных на поддержание энтропии на генетически заданном уровне.

Несколько слов о системе здравоохранения страны.

Главная проблема страны сегодня, обозначенная В.В.Путиным, - доходы населения. По оперативным данным Росстата, в 2019 году децильный коэффициент фондов (показывает отношение доли дохода, принадлежащей $10 \%$ наиболее обеспеченной части населения, к доли дохода, принадлежащей 10\% наименее обеспеченного населения) - 15,6 раза. Наличие рыночного и планового секторов медпомощи обусловлено необходимостью увеличения объема медпомощи населению страны. Рыночный сектор предназначен для высокодоходной части населения, а государственный - для остальной части населения. И здесь речь идет не о качестве медпомощи, а об удобствах её получения.

\section{Библиографический список}

1. Адам Смит. Исследование о природе и причинах богатства народов. Глава $\mathrm{V}$ «О фактической и номинальной цене товаров или об их цене в труде и их цене в деньгах».

2. Беденко Н.Н. Управление качеством в здравоохранении Тверь, 2019

3. Большая Российская энциклопедия, (Г. Д. Гловели).

4. Бережливая поликлиника: опыт внедрения инструментов бережливого производства в учреждениях Федерального медико-биологического агентства России/ М. В. Забелин, О. А. Касымова, В. В. Миронова, И.В. Кононова// Здравоохранение, образование и безопасность. -2018 . - № 4

5. Гуськова М.Ф., Стерликов П. Ф., Стерликов Ф.Ф. Ценность, полезность и стоимость образовательных услуг. М., Экономические науки, 2003

6. Ильясова А.Р. Основы экономики здравоохранения: учебник/ А. Р.Ильясова.- Казань: Казанское издательство. ун-та, 2019

7. Князюк Н.Ф., Кицуль И. С. Методология построения интегрированной системы управления медицинскими организациями. Москва: Издательский дом «Менеджер здравоохранения», 2013

8. Свиридова Т. Л. Шагни из прошлого. Руководство по психотерапии травмы. Иэд-во: Городец, 2017.

9. Стерликов Ф.Ф. Количественная определенность единицы продукта труда как общественной потребительной стоимости. М., Изд-во МГУ, 1980; 
10. Стерликов Ф.Ф. Методология анализа взаимосвязи качества продукции и цены. М.: ИЭ АН СССР, 1991

11. Столяров С.А. Менеджмент в здравоохранении учебник для вузов 2-е издание, Москва: Юрайт, 2019;

12. Шматкова В. Медицинский маркетинг: взгляд предпринимателя. Издатель: Практическая медицина:, 2021

13. Экономика здравоохранения. Под научной редакцией М. Г. Колосницыной, И. М.Шеймана, С. В.Шишкина. Издательство Высшей школы экономики, 2009.

14. Гуськова М.Ф., Стерликов П. Ф., Стерликов Ф.Ф. О синтезе экономических теорий стоимости и полезности. Монография. Варшава: ДК-ДРУК, 2007.

15. Guskova M.F., Sterlikov P.F., Sterlikov F. F. About the synthesis of economic theories of cost and utility. Monografiya. Warszava: DK-DRUK, 2007. 